\title{
Climate Change and Sustainability in Czech Wheat Production
}

Pavlína Hálová, Jiří Mach, Lukáš Čechura, Josef Slaboch

Faculty of Economics and Management, Czech University of Life Sciences Prague, Czech Republic

\begin{abstract}
The paper deals with the analysis of Czech wheat production and its determinants. We use the Just and Pope (1979) stochastic production function to estimate the effects of economic and weather variables, together with technological progress and climate change, on wheat yield in the Czech regions in the period 1961-2018. The results suggest that both economic and environmental factors play important roles in the wheat yield function. The output/input price ratio has a positive effect on the wheat yield. The effects of temperature and precipitation are month-specific and highly non-linear. Technological change also has a positive effect on yield, whereas climate change has a rather negative effect on wheat yield.
\end{abstract}

\section{Keywords}

Cereals, production, yield, weather, precipitation, economic loss.

Hálová, P., Mach, J., Čechura, L. and Slaboch, J. (2021) "Climate Change and Sustainability in Czech Wheat Production", AGRIS on-line Papers in Economics and Informatics, Vol. 13, No. 4, pp. 9-18. ISSN 1804-1930. DOI 10.7160/aol.2021.130402.

\section{Introduction}

The world's population is expected to exceed 9 billion people in 2050 (Alexandratos and Bruinsma, 2012). Thus, it is essential that the problem of ensuring global food security is addressed in the near future. A sufficient amount of food for the entire population depends greatly on the sustainable production of crops and livestock. Beddington et al. (2012) pointed to the current threat of global climate change, which requires major local and global interventions in current patterns of food production, distribution and consumption to be made/implemented. Investment, innovation and joint efforts will be needed to secure the situation of the world's most vulnerable populations. There is a need to build a stable global food system that adapts to climate change, ensures food security, minimizes greenhouse gas emissions and, at the same time, is in line with sustainable development. A significant increase in investments in sustainable agriculture, including the improvement of supporting infrastructure and the restoration of ecosystems, is an essential and necessary part of long-term economic development. The sooner these investments are made, the greater the benefits. The scientific community plays a key role in meeting the global challenges of moving the world into a safe operating space, where agriculture can meet global food-supply needs while reducing greenhouse gas emissions at the same time.
In general, climate change typically has a negative impact on the agricultural sector. However, for example, for northern European countries, rising temperatures have a positive effect on crop yields per hectare, especially for wheat or corn (King et al., 2018; Morel et al., 2021Sub-Saharan Africa (Hoffman et al., 2018, Challinor et al., 2015) and South Asia (Khanal et al., 2018) appear to be the most vulnerable areas. However, this fact is valid not only for the least developed and developing countries, but also for the developed countries. Numerous studies confirm that increasing temperatures, along with longer and recurrent dry periods / periods of drought, have a negative impact worldwide on yields of primary crops, namely wheat, corn, and rice (Knox et al., 2012), but also groundnuts and other crops (Khanal et al., 2018).

Numerous studies investigating the effects of weather changes have been done in recent years. Robertson et al. (2007) described the impact of precipitation on the scattering of US crop yields. He found that the models depend on the precipitation in terms of correlation and root mean square error. The effects of year-on-year variability and trends in temperature, solar radiation and rainfall in the years 1961-2003 were investigated by Chen et al. (2013), in particular for wheat and maize yields in the double-cropping system in Beijing and Zhengzhou. He examined the relative contributions of individual climate variables separately. The Agricultural Production Systems Simulator 
(APSIM) was used to study crop yields under a set of generated climate scenarios. The results showed that the warming trend did not have a significant effect on the wheat yield in both localities, however it had a significant negative impact on the maize yield in Beijing. Lobell et al. (2007) analysed the relationship between crop yield and three climatic variables (precipitation, maximum and minimum temperature) for 12 major California crops between 1980 and 2003. The environmental variables, most important for each crop, were used in regression model for yield. Relatively simple models using only 2-3 variables explained more than two-thirds of the observed yield variance of the majority of crops. The results show that crop infection, pollination, and dormancy may represent important mechanisms by which climate affects crop yield.

De Wit et al. (2005) expressed the effect of precipitation and radiation uncertainty on the results of a local crop yield simulation and on a regional scale (NUTS1 regions). Two experiments were performed, simulating crop yields for winter wheat and maize for grain, using the Crop Growth Monitoring System (CGMS) for the year 2000 with different precipitation and radiation inputs. The experiments suggest that the uncertainty in precipitation and radiation translates into considerable uncertainty in the crop yield at the $50 \times 50 \mathrm{~km}$ grid level. Then, the yield statistics from EUROSTAT and the output of the CGMS model for maize in the period 1990-1999 were used to develop yield models for France and Germany. These models showed that the uncertainty of radiation and precipitation in CGMS has little effect on the prediction of CGMS yield at the national level.

Many authors are concerned not only with quantification of climate influences but also with the impact of technical and economic factors on the yield of main crops in a sown area (acreage). Early studies addressed mainly the effects of temperature, precipitation, and technological progress, represented by a linear or quadratic trend for crop yield. It was found that, in principle, there is a positive effect of precipitation and a negative relationship between temperature and yields. A comprehensive meta-analysis predicting the effects of climate change on wheat yield was presented by Wilcox and Makowski (2014). In terms of methodology, the available publications pursue two directions. The first group of studies uses experiments and measures, among other things, the effects of $\mathrm{CO} 2$ increases on crop yields (Amthor, 2001) directly. The second group is based on the application of regression analysis to all types of underlying data, from crosssectional surveys through time series to panel data. Articles based on cross-sectional data obtained through a questionnaire survey also often address the influence of farmers' decision-making for adopting climate change adaptation strategies (Khanal et al., 2018, Füssel, 2007). Omitting this aspect can also lead to overestimated results.

Analysis by Hoffman et al. (2018) demonstrates that although improvements in technology have a positive effect on crop yields, warmer and drier climates have a negative effect. For instance, maize shows that there is an increase in yields of up to $13 \mathrm{~kg} / \mathrm{ha}$, but climate change can reduce current production by up to $10 \mathrm{~kg} / \mathrm{ha}$. The volatility of yields, dynamics of plant growth and time development are typical characteristics of crop modelling. This approach uses the stochastic production functions in accordance with assumptions about the random component (Just and Pope, 1979). Most articles provide results concerning the effects of future climate change on crop yields by using crop models and climate change scenarios. Weather data (temperature, precipitation) are the explanatory variables and are considered direct factors, but genetic improvements in the form of adoption of new varieties, soil characteristics, greater application of fertilizers, management practices, and indicators of adaptation to changed conditions are also considered (Qiao et al., 2018; Challinor et al., 2015).

However, only a few studies deal with the impact of climate change on primary agricultural production in terms of crop area. Other indirect factors that should not be neglected in the models are discussed here. Input prices, output prices, crop rotation and biological or agronomic factors are important determinants (Hendricks et al., 2014). More recent studies also take into account risk spreading, land constraint and the multiple output profit function of agriculture (Weersink et al., 2010). Omitting these variables, especially crop prices, can distort the effects of climate change on their yields by $9 \%$ (corn) - $15 \%$ (soybeans), see Miao et al. (2016). Studies typically differ in the way they measure climate variables, as well as in the level of data aggregation. The situation described above can be appropriately captured using panel-based models. Their advantage is the ability to estimate the linear and nonlinear influence of air temperature and the interaction between precipitation and temperature. All these are in line 
with other factors, including input, output prices and agronomic factors.

A common approach to study the climate change effects on crop yields is to use statistical models. These models are based on historical yields and some simplified weather measurements, such as average temperature during the growing season and precipitation. There are several strengths and weaknesses of this approach. For example, Lobell and Burke (2010) used a perfect model approach to examine the ability of statistical models to predict yield responses to changes in average temperature and precipitation, as simulated by a crop-process-based model. Then, the Crop Environment Resource Synthesis (CERES)-Maize model was used to simulate the historical variability of maize yields at nearly 200 sites in Sub-Saharan Africa with different scenarios. Three types of statistical model (time series, panel, and cross-disciplinary models) were then tested for simulated historical variability and used to predict responses to future climate change. The results suggest that statistical models, compared to CERES-Maize, are a useful, albeit imperfect, tool for designing future yield responses, with higher utility on a wider spatial scale. It is on these broader scales that climate projections are the most accessible and reliable, and it is therefore likely that statistical models will continue to play an important role in predicting the future impacts of climate change.

The pronounced effects of climate change on Czech agriculture in recent years have stimulated research activities in this area. For example, Čechura et al. (2020) studied the impact of climate change on cereal production in $\mathrm{Czech}$ regions. Čechura et al. (2015) related the effects of climate change to the total factor productivity (TFP) growth in Czech agriculture. The authors concluded that some effects are systemic, i.e. they affect all sectors, but they also identified idiosyncratic factors, especially in animal production. Moreover, Halova et al. (2015) provide a broader perspective, in relation to the production of public goods in Czech agriculture (water quality and availability, agricultural land biodiversity, flood resistance, soil functionality, air quality, climate stability, etc.).

In the Czech Republic, wheat production dominates crop production and, as such, represents one of the most important agricultural outputs of the country. From a total sowing area of 2.5 million ha, cereals account for $56 \%$. The largest share is held by wheat, at $62 \%$. Barley accounts for $23 \%$, corn $6 \%$, oats almost $3 \%$ and rye less than
$2 \%$. However, the structure of cereal production has been changing considerably from a long-term perspective. At the beginning of the 20th century, rye with $35 \%$ and oats with $30 \%$ dominated cereal production. Wheat was cultivated on less than $20 \%$ of the sowing area. A steady increase in wheat on the cost of rye and oat production was experienced up to the 1970s. The reasons for these changes were not only the requirements for sufficient quantities of food supply, together with an emphasis on the profitability of the sector through higher yields, but also changes in consumer preferences. Currently, the highly important problem of crop cultivation is climate change. In this respect, pronounced extreme variations in daily temperature and changes in the distribution of precipitation, in particular, have negative effects.

The aim of the paper is to quantify the impact of economic and environmental variables, as well as the impact of climate change, on wheat yields in the Czech Republic using the stochastic production function, and to evaluate how technological progress may contribute to sustainable wheat production in the Czech Republic. The estimate of the production function is based on panel data representing the average wheat yields in individual regions of the Czech Republic for the period 1961-2018. The long panel dataset allows us to distinguish between the effects of employed variables, and to separate the impact of climate change. In this respect, the paper aims to fill the gap in empirical literature on the assessment of the environmental dimension of Czech wheat production, as well as the impact of climate change.

The paper is organized as follows. The next section describes the data and methods. Then the results are presented. The final section provides concluding remarks and a discussion of the results.

\section{Materials and methods}

The yield function specification is based on the Just and Pope (1979) stochastic production function:

$y=f(X)+h(X)^{\frac{1}{2}} \varepsilon$

where $h(\boldsymbol{X})^{\frac{1}{2}}$ is a function of regressors in $\boldsymbol{X}$, $\boldsymbol{y}$ represents the yield and $\boldsymbol{\varepsilon}$ stands for residual term which is assumed to be i.i.d. $\boldsymbol{N}\left(\mathbf{0}, \boldsymbol{\sigma}_{\varepsilon}^{2}\right)$. There are at least two advantages of the Just and Pope specification (1) (i.e. with $h(\boldsymbol{X})^{\frac{1}{2}}$ term) over a standard approach. First, in the latter case, the risk of production is not considered. That is, if we assume the risk aversion, which is the typical 
farm characteristic, the risk effect is incorrectly estimated. Second, the standard approach is typically characterized by the presence of heteroscedasticity. As a result, it makes problems in hypothesis testing about the importance of regressors, and it may decrease the efficiency of the model estimate (Just and Pope, 1979).

The estimation procedure of (1) consists of three steps. In the first step, $\mathrm{y}$ is regressed on $\boldsymbol{X}$ using ordinary least square (OLS) method. The second step uses the squared residual from the first step in the regression on $\boldsymbol{X}$ using OLS. In the third step, $y$ is regressed on $\boldsymbol{X}$ and the square root of the predictions from the second step.

The functional form of the model (1) in this study is specified as a Taylor approximation of the second order in the environmental variables. That is, we use the Taylor approximation of the second order to approximate the nonlinear relationship between wheat yield and temperature/precipitation in the respective month. In the case of the price index and moisture, we assume a linear relationship with wheat yield. Moreover, the technological change and climate change effects are captured using the trend variable ( $t$ ). In the latter case, we use trend variable in combination with temperature and precipitation variables, in order to capture the changes in the first-order parameters due to the effects of climate change. That is, we can write our model as:

$y=\alpha^{\prime} z+\beta^{\prime} x+\gamma^{\prime} x^{2}+\delta^{\prime} c+h(X)^{\frac{1}{2}} \varepsilon$

where $\boldsymbol{\alpha}, \boldsymbol{\beta}, \boldsymbol{\gamma}, \boldsymbol{\delta}$ are vectors of parameters to be estimated. $\boldsymbol{z}, \boldsymbol{x}$ and $\mathbf{c}$ are vectors of regressors.

The vectors of regressors $\boldsymbol{z}, \boldsymbol{x}$ and $\boldsymbol{c}$ consist of the following variables (variables are logarithmically transformed and normalized by their mean):

$z:$

- $\quad$ P_index_ratio - (IPP) - a ratio of wheat price index over composite price input index.

- Moisture - (IMo) - average of precipitation from November to March.

$x:$

- Monthly temperatures - (ITM4,...,ITM7) - average monthly temperatures from April to July.

- Monthly precipitation - (ISM4,..., ISM7) - average monthly precipitation from April to July. $c:$

- Climate change variables - (IT4_t,... $\left.I T 7_{-} t, l S 4 \_t, \ldots, l S 7_{-} t\right)$ - average monthly temperatures and precipitation in combination with the time vector.

- Time vector - ( $t$ and $\left.t \_2\right)$ - a proxy for technological change.

The study uses panel data representing the average wheat yields, price indices, monthly temperatures and precipitation in individual regions of the Czech Republic for the period 1961-2018. The source of the data is the Czech Statistical Office (www.czso.cz) and the Czech Hydrometeorological Institute (www.chmi.cz). The basic statistical characteristics of the variables are provided in the Appendix.

In our empirical application, we exploit the properties of the long panel dataset, i.e. small $\mathrm{N}$ and large $\mathrm{T}$, and we use the fixed effects model estimator. In particular, Pesaran (2015) shows that there is no difference between the fixed or random effects model estimator when $\mathrm{N}$ is small and $\mathrm{T}$ large.

SW GRETL was used to estimate model (2).

\section{Results and discussion}

Table 1 provides a parameter estimate of the yield function in a Just and Pope specification. The estimate displays an overall good fit. In particular, the estimate is consistent with economic and agronomical assumptions. Then, the majority of fitted parameters are significant even at a $1 \%$ significance level. The variability of yield is well explained by the regressors (LSDV R2 $=0.87$ ), and the assumptions regarding the residual term are met by the estimate as well.

\begin{tabular}{l|c|c|c}
\hline Variable & Coefficient & $\begin{array}{c}\text { Standard } \\
\text { Deviation }\end{array}$ & p-value \\
\hline const & 5.697 & 1.784 & 0.002 \\
IPP & 0.651 & 0.067 & 0.000 \\
IT4 & -0.051 & 0.087 & 0.559 \\
1T5 & -0.989 & 0.113 & 0.000 \\
1T6 & 2.644 & 0.853 & 0.002 \\
1T7 & -0.799 & 0.125 & 0.000 \\
1T4_2 & 3.932 & 1.725 & 0.023 \\
1T5_2 & -6.053 & 2.330 & 0.010 \\
1T6_2 & 0.621 & 0.204 & 0.002 \\
1T7_2 & -12.841 & 3.331 & 0.000 \\
\hline
\end{tabular}

Source: author's own calculation

Table 1: Estimated parameters of the stochastic production function (to be continued). 


\begin{tabular}{l|c|c|c}
\hline Variable & Coefficient & $\begin{array}{c}\text { Standard } \\
\text { Deviation }\end{array}$ & p-value \\
\hline 1Mo & 0.023 & 0.019 & 0.244 \\
IS4 & -0.002 & 0.010 & 0.810 \\
1S5 & 0.040 & 0.011 & 0.000 \\
1S6 & -0.067 & 0.012 & 0.000 \\
1S7 & -0.066 & 0.010 & 0.000 \\
1S4_2 & -0.028 & 0.014 & 0.044 \\
1S5_2 & -0.093 & 0.024 & 0.000 \\
1S6_2 & -0.232 & 0.038 & 0.000 \\
1S7_2 & -0.032 & 0.017 & 0.065 \\
1T4_t & 0.009 & 0.006 & 0.134 \\
1T5_t & -0.063 & 0.009 & 0.000 \\
1T6_t & 0.004 & 0.002 & 0.050 \\
1T7_t & 0.037 & 0.010 & 0.000 \\
1Mo_t & 0.004 & 0.001 & 0.000 \\
1S4_t & 0.000 & 0.001 & 0.570 \\
1S5_t & -0.002 & 0.001 & 0.002 \\
1S6_t & -0.001 & 0.001 & 0.409 \\
1S7_t & 0.002 & 0.001 & 0.000 \\
t & 0.040 & 0.008 & 0.000 \\
t_2 & 0.000 & 0.000 & 0.000 \\
\hline Sourc: & & &
\end{tabular}

Source: author's own calculation

Table 1: Estimated parameters of the stochastic production function (continuation)

Since variables were logarithmically transformed and normalized by their means, the first-order parameters can be interpreted as elasticities when evaluated on sample means. That is, a particular first-order parameter provides information on the percentage change in wheat yield in a reaction to a $1 \%$ change in the respective explanatory variable evaluated on the sample mean. In this respect, the parameter on price index (1PP) shows that a $1 \%$ change in the ratio of wheat output and composite input price indices results in a $0.651 \%$ change in wheat yield. This positive effect of the price index is consistent with the economic expectation concerning the effect of price on the yield. Hendricks (2014) makes similar conclusions. In particular, an increase in the wheat index over the composite input index stimulates farmers to increase the allocation of a higher portion of quality land in the production of wheat, resulting in a higher wheat yield, on average.

Temperature shows the greatest impact on wheat yield. The first-order parameters suggest that temperature has a negative effect in April, May and July, and a positive effect in June (with respect to the mean).It is in accordance with King et al.(2018) and Morel et al (2021). The second-order parameter reinforces the negative effect in May and July, as well as the positive effect in June. In particular, high nonlinearity is pronounced in May and July. It holds that the higher the temperatures (above-average temperatures) are in May and July, the higher wheat yield losses we can expect. On the other hand, the second-order parameter in April changes the negative effect to a positive one, with higher temperatures above the average.

The temperature effects for different months and different years are depicted in Figures 1a, b, c, d. In addition, the figures capture the estimated climate change effect. That is, the model estimate shows that the first-order parameters are changing over time (see parameters on 1T4_t, .., 1T7_t). Whereas the parameters in April, June and July are going up, the negative effect in May is more and more pronounced. Since we can associate these parameter changes with the effects of climate change, Figures 1a,b,c,d demonstrate how these climate change effects determine the changes in wheat yield over time. In particular, we can observe the differences between the years 1990, 2020 and 2050 according to our estimates.

Moisture shows a positive, but not a significant effect on wheat yield. However, the minor increase in the positive effect due to climate change is significant, even at the $1 \%$ significance level. The estimated effect of precipitation is negative in April, June and July, and there is a positive effect in May. The second-order parameters suggest that the higher precipitation is above the average in April, June and July, the greater is the negative effect on wheat yield. On the other hand, the positive effect of precipitation in May deteriorates with an increase in temperatures above the average.

The climate change effect (1S4_t, .., 1S7_t) is significant in May and July. We can observe a decrease in the positive effect of May, and a decrease in the negative effect of July (as far as the first-order parameters are concerned). Figures 2a, b, c, d demonstrate how the climatechange effects on precipitation determine the changes in wheat yield over time.

Finally, we estimated the positive effect of technological change. That is, we can observe that advances in $R \& D$ positively contributed to wheat yield. The effect accounts for, on average, a $0.04 \%$ increase per year. Then, we found significant heterogeneity among the Czech regions. 


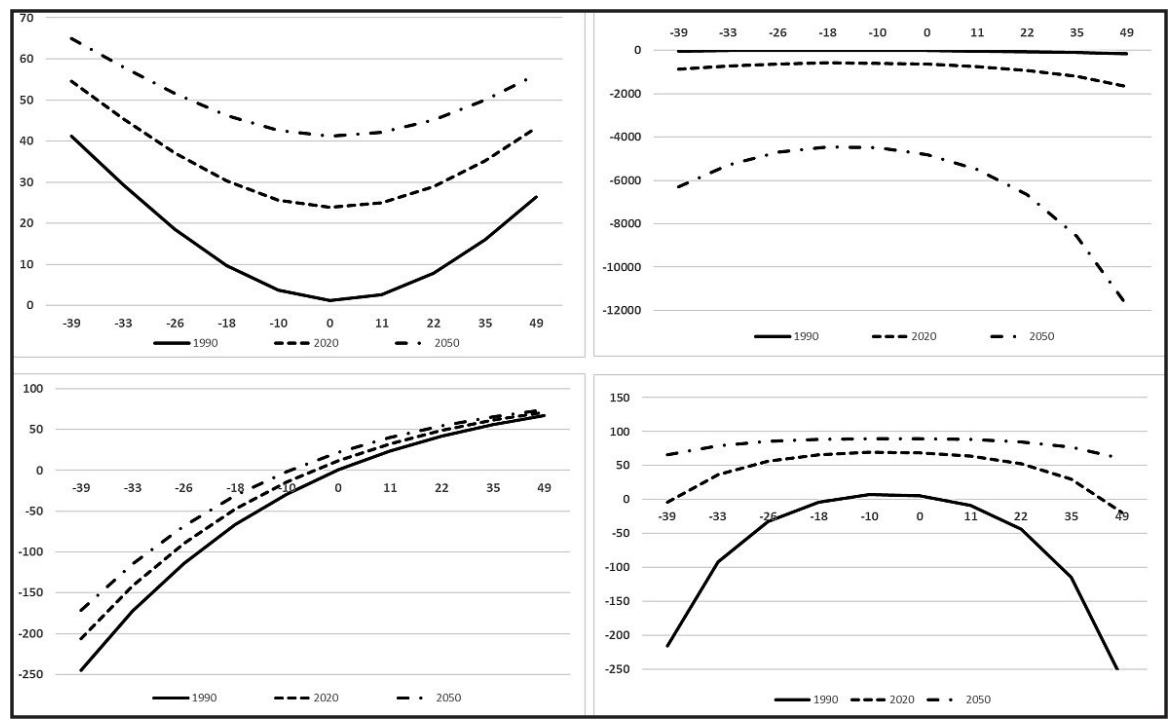

Note: a) April, b) May, c) June, d) July

Legend: $\mathrm{x}$-axis - $\%$ change in temperature with respect to the mean of the respective month; $y$-axis

- $\%$ change in the wheat yield with respect to the sample mean.

Source: author's own calculation

Figure 1a, b, c, d: Climate change effect on the changes in yield - temperatures.

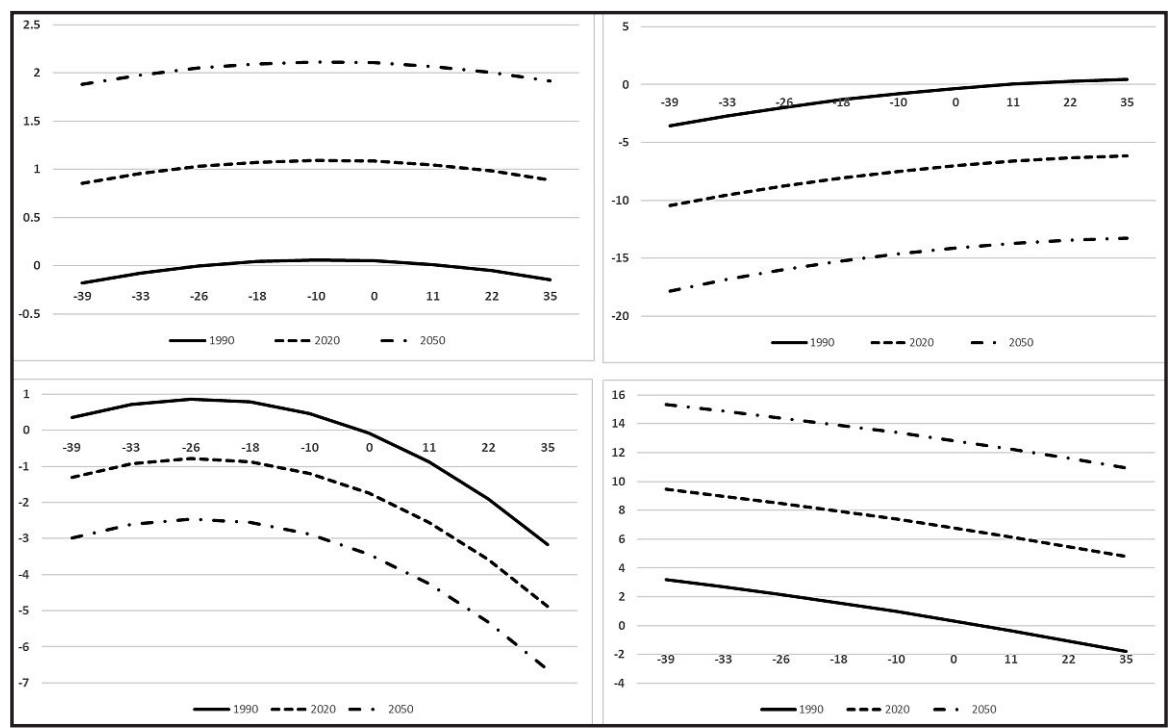

Note: a) April, b) May, c) June, d) July

Legend: $\mathrm{x}$-axis - $\%$ change in temperature with respect to the mean of the respective month; $\mathrm{y}$-axis

- $\%$ change in the wheat yield with respect to the sample mean.

Source: author's own calculation

Figure 2a, b, c, d: Climate change effect on the changes in yield - precipitation.

In particular, the fixed effects suggest that yield differences between the Czech regions are another important characteristic of Czech wheat production.

\section{Conclusion}

The aim of this study was to demonstrate and quantify the effects of economic and environmental factors, as well as climate change, on the yields of wheat grown in the Czech Republic. The study uses panel data constructed for individual regions of the Czech Republic for the period 1961-2018. Wheat yields are explained by price index, monthly temperatures in the period of growth, precipitation, moisture, climate change and technological change. A stochastic production function was applied to model the effects of selected variables.

The largest and most positive effect $(2.644 \%)$, by far, is evident for temperature in June, which is still supported by the second-order parameter. 
On the other hand, a significant negative effect is evident for higher temperatures in May and July. This finding is also reinforced by the secondorder parameter and is in line with the appropriate conditions for growing this type of cereal. The second most important variable is the price index, which has a positive effect $(0.651 \%)$. From an economic point of view, it is also expected that favorable output prices motivate farmers to produce more.

Another significant determinant is the precipitation in individual months. It is obvious that it has a positive effect in the spring months, contrary to the time of grain ripening and harvesting. It has the largest positive effect in May $(0.04 \%)$ and the highest negative effect in June $(0.06 \%)$. The fourth most important variable is climate change, which confirms the negative impact of high temperatures in May. On the contrary, warming in the summer months has a positive effect.

In the evaluation of the influence of selected factors, technological progress is next in line; its positive effect is confirmed by an elasticity of $0.04 \%$. The last positive, although statistically insignificant effect, was demonstrated for the variable moisture.

The results show that climate change, in the form

Corresponding authors

Ing. Pavlína Hálová, Ph.D.

Department of Economics, Faculty of Economics and Management

Czech University of Life Sciences Prague, Kamycka 129, Prague - Suchdol, 165 00, Czech Republic

E-mail: halova@pef.czu.cz

\section{References}

[1] Alexandratos, N. and Bruinsma, J. (2012) "World agriculture towards 2030/2050: the 2012 revision", ESA Working paper, No. 12-03. Rome, FAO. [Online]. Available: https://www.fao.org/3/ap106e/ ap106e.pdf [Accessed: 25 Aug, 2021].

[2] Amthor, J. S. (2001) "Effects of atmospheric $\mathrm{CO}_{2}$ concentration on wheat yield: review of results from experiments using various approaches to control $\mathrm{CO}_{2}$ concentration", Field Crops Research, Vol. 73, No. 1, pp. 1-34. ISSN 0378-4290. DOI 10.1016/S0378-4290(01)00179-4.

[3] Beddington, J. R., Asaduzzaman, M., Clark, M. E., Bremauntz A. F., Guillou, M. D., Jahn, M. M., Erda, L., Mamo, T., Negra, Ch., Nobre, C. A., Scholes, R. J. L., Sharma, R., Van Bo, N. and Wakhungu, J. (2012) "The role for scientists in tackling food insecurity and climate change", Agriculture \& Food Security, Vol. 1, No. 10. ISSN 2048-7010. DOI 10.1186/2048-7010-1-10.

[4] Čechura, L., Kroupová, Z. and Rudinskaya, T. (2015) "Factors determining TFP changes in Czech agriculture", Agricultural Economics, Vol. 61, No. 12, pp. 543-551, ISSN 0139-570X. DOI 10.17221/14/2015-AGRICECON.

[5] Čechura, L., Hálová, P. and Mach, J. (2020) "Technological progress, weather effects and sustainability in Czech cereal production", $29^{\text {th }}$ International Scientific Conference Agrarian Perspectives XXIX. Trends and Challenges of Agrarian Sector, pp. 83-89. ISSN 2464-478. 
[6] Challinor, A. J., Parkes, B. and Ramirez-Villegas, J. (2015) "Crop yield response to climate change varies with cropping intensity", Global Change Biology, Vol. 21, No. 4, pp. 1679-1688. ISSN 1365-2486. DOI 10.1111/gcb.12808.

[7] Chen, C., Baethgen, W. E. and Robertson, A. (2013) "Contributions of individual variation in temperature, solar radiation and precipitation to crop yield in the North China Plain, 1961-2003", Climatic Change, Vol. 116, pp. 767-788. E-ISSN 1573-1480, ISSN 0165-0009. DOI 10.1007/s10584-012-0509-2.

[8] De Wit, A. J. W., Boogaard, H. L. and van Diepen, C. A. (2005) "Spatial resolution of precipitation and radiation: The effect on regional crop yield forecasts", Agricultural and Forest Meteorology, Vol. 135, No. 1-4, pp. 156-168. ISSN 0168-1923. DOI 10.1016/j.agrformet.2005.11.012.

[9] Füssel, H.-M. (2007) "Adaptation planning for climate change: concepts, assessment approaches, and key lessons", Sustainability Science, Vol. 2, pp 265-275. E-ISSN 1862-4057, ISSN 1862-4065. DOI 10.1007/s11625-007-0032-y.

[10] Hálová, P., Žáková Kroupová, Z., Havlíková, M., Čechura, L. and Malý, M. (2015) "Provision of Public Goods in Czech Agriculture", Proceedings of the $24^{\text {th }}$ International Scientific Conference on Agrarian Perspectives - Global Agribusiness and the Rural Economy, Prague, pp. 145-158. ISBN 978-80-213-2581-4.

[11] Hendricks, N. P., Smith, A. and Sumner, D. A. (2014) "Crop supply dynamics and the illusion of partial adjustment", American Journal of Agricultural Economics, Vol. 96, No. 5, pp. 1469-1491. E-ISSN 1467-8276, ISSN 0002-9092. DOI 10.1093/ajae/aau024.

[12] Hoffman, A. L., Kemanian, A. R. and Forest, Ch. E. (2018) "Analysis of climate signals in the crop yield record of sub-Saharan Africa", Global Change Biology, Vol. 24, pp. 143-157. ISSN 1365-2486. DOI 10.1111/gcb.13901.

[13] Just, R. and Pope, R. (1979) "Production Function Estimation and Related Risk Considerations", American Journal of Agricultural Economics, Vol. 61, No. 2, pp. 276-284. E-ISSN 1467-8276. DOI $10.2307 / 1239732$.

[14] Khanal, U., Wilson, C., Hoang, V. and Lee, B. (2018) "Farmers' Adaptation to Climate Change, Its Determinants and Impacts on Rice Yield in Nepal", Ecological Economics, Vol. 144, pp. 139-147. ISSN 0921-8009. DOI 10.1016/j.ecolecon.2017.08.006.

[15] King, M., Altdorff, D., Li, P., Galagedara, L., Holden, J. and Unc, A. (2018) "Northward shift of the agricultural climate zone under 21st-century global climate change", Scientific Reports, Vol. 8, No. 1. E-ISSN ISSN 2045-2322. DOI 10.1038/s41598-018-26321-8.

[16] Knox, J., Hess, T., Daccache, A. and Wheeler, T. (2012) "Climate change impacts on crop productivity in Africa and South Asia", Environmental Research Letters, Vol. 7, No. 3. ISSN 1748-9326. DOI 10.1088/1748-9326/7/3/034032

[17] Lobell, D. B. and Burke, M. B. (2010) "On the use of statistical models to predict crop yield responses to climate change", Agricultural and Forest Meteorology, Vol. 150, No. 11, pp. 1443-1452. ISSN 0168-1923. DOI 10.1016/j.agrformet.2010.07.008.

[18] Lobell, D. B., Cahill, K. N. and Field, C. B. (2007) "Historical effects of temperature and precipitation on California crop yields", Climatic Change, Vol. 81, pp. 187-203. E-ISSN 1573-1480, ISSN 0165-0009. DOI 10.1007/s10584-006-9141-3.

[19] Miao, R., Khanna, M. and Huang, H. (2016) "Responsiveness of Crop Yield and Acreage to Prices and Climate", American Journal of Agricultural Economics, Vol. 98, pp. 191-211. E-ISSN 1467-8276. DOI 10.1093/ajae/aav025.

[20] Morel, J., Kumar, U., Ahmed, M., Bergkvist, G., Lana, M., Halling, M. and Parsons, D. (2021) "Quantification of the Impact of Temperature, $\mathrm{CO}_{2}$, and Rainfall Changes on Swedish Annual Crops Production Using the APSIM Model", Frontiers in Sustainable Food Systems, Vol. 5, Art. No. 665025, 11 p. ISSN 2571-581X. DOI 10.3389/fsufs.2021.665025. 
[21] Pesaran, M. H. (2015) "Time series and panel data econometrics", Oxford University Press. ISBN 9780198736912. DOI 10.1093/acprof:oso/9780198736912.001.0001.

[22] Qiao, J., Yu, D. and Wu, J. (2018) "How do climatic and management factors affect agricultural ecosystem services? A case study in the agro-pastoral transitional zone of northern China", Science of The Total Environment, pp. 314-323. ISSN 0048-9697. DOI 10.1016/j.scitotenv.2017.08.264.

[23] Robertson, A. W., Ines, A.V. M. and Hansen, J. W. (2007) "Downscaling of Seasonal Precipitation for Crop Simulation", Journal of Applied Meteorology and Climatology, Vol. 46, pp. 677-693. E-ISSN 1558-8432, ISSN 1558-8424. DOI 10.1175/JAM2495.1.

[24] Weersink, A., Cabas, J. H. and Olale, E. (2010) "Acreage Response to Weather, Yield, and Price", Canadian Journal of Agricultural Economics, Vol. 58, No. 1, pp. 57-72. E-ISSN 1744-7976, ISSN 0008-3976. DOI 10.1111/j.1744-7976.2009.01173.x.

[25] Wilcox, J. and Makowski, D. (2014) "A meta-analysis of the predicted effects of climate change on wheat yields using simulation studies", Field Crops Research, Vol. 156, pp. 180-190. ISSN 0378-4290. DOI 10.1016/j.fcr.2013.11.008. 


\section{Appendix}

\begin{tabular}{|c|c|c|c|}
\hline Variable & Number of observations & Mean & Standard Deviation \\
\hline Wheat yield & 784 & 4.28 & 1.13 \\
\hline Wheat price index & 784 & 0.75 & 0.35 \\
\hline Composite input index & 784 & 0.70 & 0.37 \\
\hline Average temperature - April & 784 & 7.64 & 1.73 \\
\hline Average temperature - May & 784 & 12.56 & 1.63 \\
\hline Average temperature - June & 784 & 15.72 & 1.44 \\
\hline Average temperature - July & 784 & 17.42 & 1.77 \\
\hline Moisture & 784 & 44.77 & 13.70 \\
\hline Average precipitation - April & 784 & 43.25 & 20.23 \\
\hline Average precipitation - May & 784 & 71.89 & 32.06 \\
\hline Average precipitation - June & 784 & 81.99 & 30.08 \\
\hline Average precipitation - July & 784 & 85.68 & 43.00 \\
\hline
\end{tabular}

Source: author's own calculation

Table A1: Descriptive statistics of model variables. 